\title{
Electrochemical oxidation of some basic alcohols on multiwalled carbon nanotube-platinum composites
}

\author{
MINSOO KOO ${ }^{1}$, JONG-SEONG BAE ${ }^{2}$, HYUN-CHUL KIM ${ }^{3}$, DAE-GEUN NAM ${ }^{4}$, \\ CHANG HYUN KO ${ }^{5}$, JEONG HYUN YEUM ${ }^{6}$ and WEONTAE OH ${ }^{1, *}$ \\ ${ }^{1}$ Department of Materials \& Components Engineering, Electronic Ceramics Centre, Dong-Eui University, \\ Busan 614-714, Korea \\ ${ }^{2}$ Division of High-Technology Materials Research, Korea Basic Science Institute, Busan 618-230, Korea \\ ${ }^{3}$ Division of Nano- \& Bio-technology, Daegu Gyeongbuk Institute of Science \& Technology, Daegu 704-230, Korea \\ ${ }^{4}$ Dongnam Regional Division, Korea Institute of Industrial Technology, Busan 618-230, Korea \\ ${ }^{5}$ School of Applied Chemical Engineering, Chonnam National University, Gwangju 500-757, Korea \\ ${ }^{6}$ Department of Natural Fibre Science, Kyungpook National University, Daegu 702-701, Korea
}

MS received 16 March 2011; revised 26 June 2011

\begin{abstract}
Some composites of multiwalled carbon nanotubes, which were chemically treated in acidic and/or hydrogen peroxide solution, and platinum nanoparticles were prepared by the simple reduction in glycerol solution. Carboxylated and/or hydroxyl MWNTs were structurally analysed using X-ray photoelectron spectroscopy. In addition, the MWNT-Pt composites were characterized by XRD and TEM in detail. The electrochemical oxidation of some basic alcohols, which was catalyzed by the MWNT-Pt composites, was analysed by cyclic voltammetry. Their catalytic activities were studied with cyclic voltammograms of alcohols.
\end{abstract}

Keywords. Multiwalled carbon nanotubes; Pt nanoparticles; alcohols; electrochemical oxidation.

\section{Introduction}

The massive increase of environmental pollution accompanied by recent industrial and economic growth has prompted interest and research activities on the clean and renewable energy. The need of these clean and renewable power sources is pushing up the commercialization of fuel cells. The fuel cell is an important energy conversion system, which can directly change chemical energy to electric energy without charge-discharge process (Chan et al 2008). Especially the fuel cell system employing alcohols (direct alcohol fuel cell, (DAFC)) is considerably attractive as power source for mobile, stationary, portable applications such as cellular phones and laptop computers because small molecular alcohols such as methanol and ethanol have high energy density per volume and good energy efficiency. Moreover, these small alcohols are easier to store and transfer than gaseous fuels.

Some metal catalysts are feasible to electrochemically oxidize organic compounds and therefore, have been studied extensively for the application of electrochemical power sources (Parsons and VandefNoot 1988). Platinum and platinum-based alloys are useful for these metal catalysts (Xia et al 1996; Liu et al 2005). Specific catalyst should be carefully selected because its activity is susceptible to the microstructures, surface conditions, compositions, morpho-

\footnotetext{
*Author for correspondence (wtoh2005@ deu.ac.kr)
}

logies, and so on. The choice of suitable supporting material is another important factor that affects the performance of metal catalyst (Uchida et al 1995; Wu et al 2005).

Carbon nanotubes (CNTs) are expected to be used as a versatile building block for the modern nanodevices and the unique support of various catalysts (Ang et al 2000; Chen et al 2000; Kong et al 2002; Yoon and Wai 2005; Hu et al 2006; Wildgoose et al 2006), due to the outstanding mechanical, chemical, and electrical properties (An et al 2001). CNT-supported catalysts such as $\mathrm{Ru}, \mathrm{Pt}$ and $\mathrm{Ru} / \mathrm{Pt}$ alloy showed excellent activities and selectivities in various chemical reactions (He et al 2004). These were mainly attributed to the improved catalyst stability caused by strong interaction with CNTs, in which mass transfer or catalytic chemical state was induced by the CNTs (Wu et al 2005). Moreover, chemical reactions of oxidation and reduction are known to favour on the defect sites of CNTs such as five- or seven-membered rings (Kim and Lee 2009). Well-dispersed Pt nanoparticles on the surfaces of CNTs showed good activity as an electrocatalyst for methanol oxidation (Morris et al 1999; Tong et al 2000). The Pt catalysts deposited on CNTs have improved the efficiency of fuel cell and promoted the selectivity of hydrogenation (Serp et al 2003; Gomes et al 2004; Garcia et al 2005; Vu et al 2006; Menard et al 2007). These catalytic reactions are considerably dependent on the structural factors such as distribution and size of the nanoparticles, synthesis and composite morphology (Qi et al 1998; Thompson et al 2001; Liu et al 2002; Wang et al 2004). 
In this work, Pt nanoparticles were prepared on the surfaces of multiwalled carbon nanotubes (MWNTs), which were chemically treated in acid and/or hydrogen peroxide solutions to modify their surfaces with carboxylic acid and hydroxyl groups. The electrochemical activities of $\mathrm{Pt}$ nanoparticles, which were embedded in the chemicallytreated MWNTs, were deliberately investigated on some basic alcohols such as methanol, ethanol, ethylene glycol and butanol.

\section{Experimental}

Multiwalled carbon nanotubes (MWNTs, CMP310F) were supplied from Hanwha Nanotech Co. Ltd. (Korea), and had the characteristics of thin wall $(\sim 5 \mathrm{~nm}$ diameter). Chloroplatinic acid hydrate $\left(\mathrm{H}_{2} \mathrm{PtCl}_{6} \cdot 6 \mathrm{H}_{2} \mathrm{O}\right)$, ethylene glycol and butanol were purchased from Sigma-Aldrich (USA) and Glycerol (99\%), ethanol, methanol, hydrogen peroxide, nitric acid and sulfuric acid from Junsei (Japan).

$600 \mathrm{mg}$ of pristine MWNTs were chemically treated in $120 \mathrm{~mL}$ of aqueous acid mixture solution $(1 / 1 \mathrm{v} / \mathrm{v})$ of $98 \%$ $\mathrm{H}_{2} \mathrm{SO}_{4}$ and $60 \% \mathrm{HNO}_{3}$, in which MWNTs were sonicated for $2 \mathrm{~h}$ and refluxed at $80^{\circ} \mathrm{C}$ for $5 \mathrm{~h}$. These acid-treated MWNTs ( $c$-MWNTs) were well washed at least three times with distilled water to reach $\mathrm{pH} \sim 6$ and dried in vacuum at $60^{\circ} \mathrm{C}$ for overnight. In order to prepare peroxide-treated MWNTs (HO-MWNTs, which were modified with hydroxyl groups), pristine MWNTs were chemically treated in 30\% $\mathrm{H}_{2} \mathrm{O}_{2}$ aqueous solution (sonication for $2 \mathrm{~h}$ and reflux at $80^{\circ} \mathrm{C}$ for $5 \mathrm{~h}$ ). Further $\mathrm{H}_{2} \mathrm{O}_{2}$ treatment was conducted on $c$ MWNTs in order to prepare both acid- and peroxide-treated MWNTs ( $c(\mathrm{HO})-\mathrm{MWNTs})$.

MWNT-Pt composites were prepared by the method described in literature (Selvaraj et al 2008); $500 \mathrm{mg}$ of $\mathrm{H}_{2} \mathrm{PtCl}_{6} \cdot 6 \mathrm{H}_{2} \mathrm{O}$ as $\mathrm{Pt}$ precursor was dissolved in $100 \mathrm{~mL}$ of glycerol aqueous solution (glycerol/ $\mathrm{H}_{2} \mathrm{O}, 3: 1 \mathrm{v} / \mathrm{v}$ ) and sonicated for $20 \mathrm{~min} .140 \mathrm{mg}$ of $c$-MWNTs was separately added to $90 \mathrm{~mL}$ of glycerol aqueous solution (glycerol/ $\mathrm{H}_{2} \mathrm{O}, 3: 1 \mathrm{v} / \mathrm{v}$ ) and sonicated for $1 \mathrm{~h}$. Then the Pt precursor solution was slowly added to $c$-MWNT solution, and sonicated for $1 \mathrm{~h}$. This mixture solution was further refluxed for $12 \mathrm{~h}$ at $120-130^{\circ} \mathrm{C}$ to prepare $c$-MWNT composite with $\mathrm{Pt}$ nanoparticles ( $c$-MWNT-Pt). The resulting mixture solution was filtered out and dried in vacuum oven at $70^{\circ} \mathrm{C}$ for overnight. The same procedure was separately conducted to prepare $\mathrm{HO}-\mathrm{MWNT}$ and $c(\mathrm{HO})-\mathrm{MWNT}$ composites with $\mathrm{Pt}$ nanoparticles.

X-ray photoelectron spectroscopic (XPS) data were measured by VG Scientific Escalab 250 at KBSI (Busan, Korea).
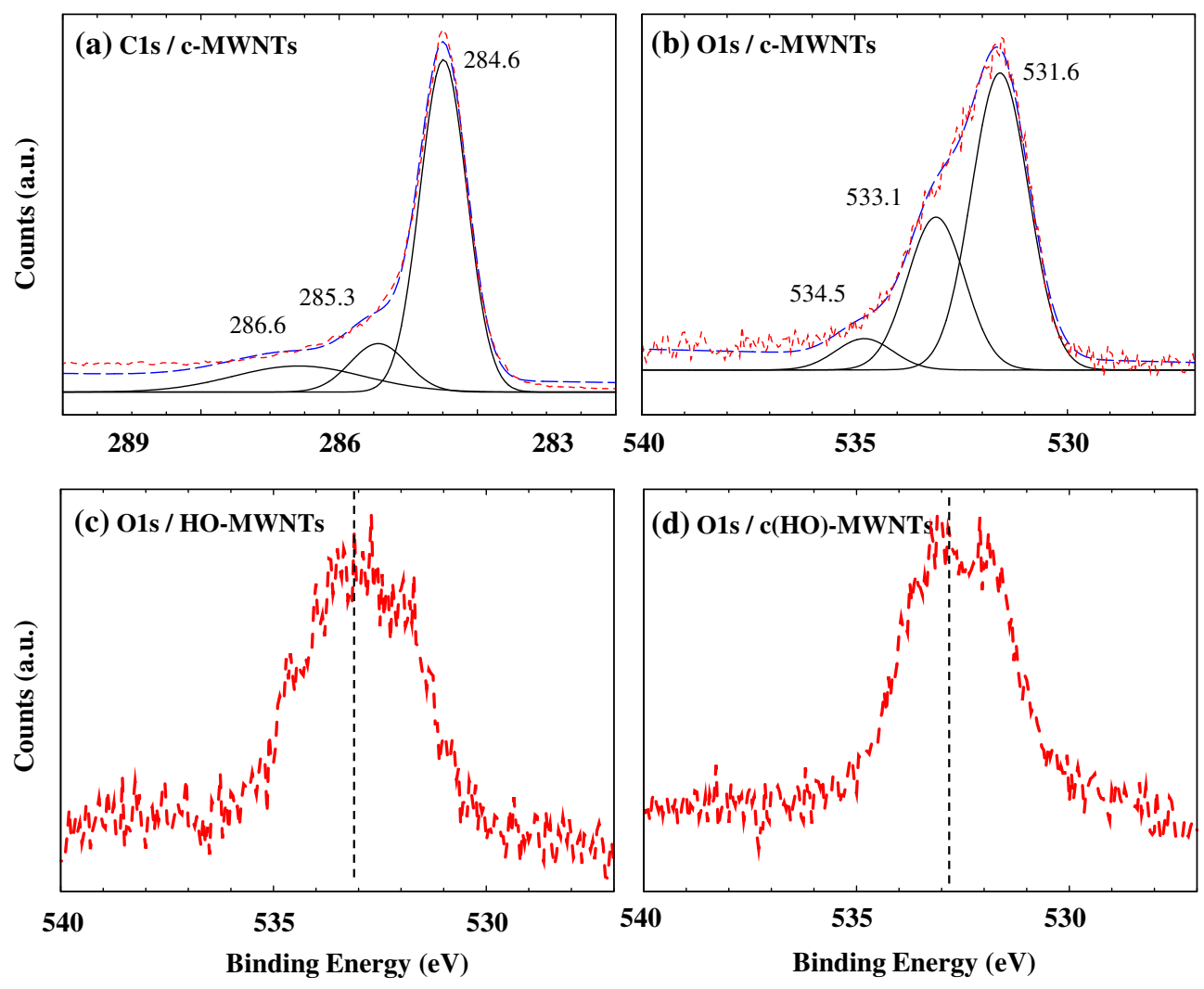

Figure 1. XPS spectra of chemically-treated MWNTs, which were modified with (a)-(b) carboxylic acid (c-MWNTs), (c) hydrogen peroxide (HO-MWNTs), and (d) carboxylic acid and hydrogen peroxide ( $c(\mathrm{HO})-\mathrm{MWNTs})$. The spectra of (a)-(b) were deconvoluted. Short- and long-dotted lines, and solid lines represent experimental and fitted data, and the fitted elements, respectively. 
All of the binding energies were determined with the $\mathrm{C} 1 \mathrm{~s}$ core level peak at $284.6 \mathrm{eV}$ as a reference. X-ray diffraction (XRD) patterns were collected using an X-ray diffractometer (PANalytical X/pert Pro MPD) equipped with a reflection geometry and a fixed anode X-ray generator of a $\mathrm{CuK} \alpha$ radiation source. Transmission electron microscopic (TEM) images were obtained in JEOL 2010F microscopes. Cyclic voltammetry $(\mathrm{CV})$ was carried out in $0.5 \mathrm{M} \mathrm{H}_{2} \mathrm{SO}_{4}$ using an electrochemical workstation (BioLogic HCP-803) with a platinum gauze counter electrode and a SCE reference electrode, and the composite thin films were deposited on a gold-deposited Si wafer. A scan rate of $50 \mathrm{mV} / \mathrm{s}$ was used for the measurement. UV/Vis spectra were collected using a SCINCO-S3100 spectrophotometer with water as blank in the range of $400-800 \mathrm{~nm}$.

\section{Results and discussion}

The chemical modification of MWNTs could be definitely identified by analysing stoichiometry and binding energy of each element obtained from XPS measurement (Sharma et al 2006). Figure 1 shows XPS results of MWNTs, which were chemically treated in acidic and/or hydrogen peroxide solutions. The oxidation of MWNTs by chemical treatment such as acid and/or hydrogen peroxide altered the chemical status of their surfaces, and correspondingly made the additional binding energies of $\mathrm{O} 1 s$, which were obtained from carboxylic acid $(-\mathrm{COOH})$ and hydroxyl groups $(-\mathrm{OH})$.
Moreover, the peak intensity of $\mathrm{O} 1 s$ binding energy significantly increased as compared to pristine MWNTs (not shown here). The binding energies of carbon $(\mathrm{C} 1 s)$ and oxygen $(\mathrm{O} 1 s)$, which were measured on chemically-treated MWNTs, were represented in figures $1 \mathrm{a}-\mathrm{d}$. Two additional peak elements at 286.6 and $285.3 \mathrm{eV}$ were identified in $\mathrm{C} 1 \mathrm{~s}$ peak of $c$-MWNTs, which were located in the higher binding energy than the $\mathrm{C} 1 s$ core level energy at $284.6 \mathrm{eV}$. These are assigned for the carbons of $-\mathrm{C}=\mathrm{O}$ and $-\mathrm{C}-\mathrm{O}$. In cases of $\mathrm{HO}-$ and $c(\mathrm{HO})-\mathrm{MWNTs}$, the $\mathrm{C} 1 s$ peaks were also similar to the C1s peak of $c$-MWNTs, which were caused by some amounts of natural oxides in their surfaces. However, the peak shapes of $\mathrm{O} 1 s$ were slightly changed depending on chemical modifications of MWNTs. We could distinguish the characteristic oxygen peak elements of $c$-MWNTs from the deconvoluted results of $\mathrm{O} 1 s$ peak; $531.6 \mathrm{eV}$ for $\mathrm{C}=\mathrm{O}$, $533.1 \mathrm{eV}$ for $-\mathrm{C}-\mathrm{O}-\mathrm{H}$, and $534.5 \mathrm{eV}$ for $-\mathrm{C}-\mathrm{O}-$. As compared to $\mathrm{O} 1 s$ peak of $c-\mathrm{MWNTs}, \mathrm{O} 1 s$ peaks of $\mathrm{HO}-$ and $c(\mathrm{HO})-\mathrm{MWNT}$ were symmetrically and broadly shaped as shown in figures $1 \mathrm{c}-\mathrm{d}$. Moreover, their peak maxima moved up to $\sim 533 \mathrm{eV}$, which represents the binding energy of $-\mathrm{C}-\mathrm{O}-\mathrm{H}$. On the other hand, the peak element of carbonyl oxygen was relatively obscure in the O1s peaks. Conclusively, these XPS results proved that the surface of MWNTs was differently modified by the change of chemical treatment method.

Figure 2 showed XRD patterns and TEM images of chemically-treated MWNT composites with Pt nanoparticles. The strong diffraction peaks, (111), (200) and (220),

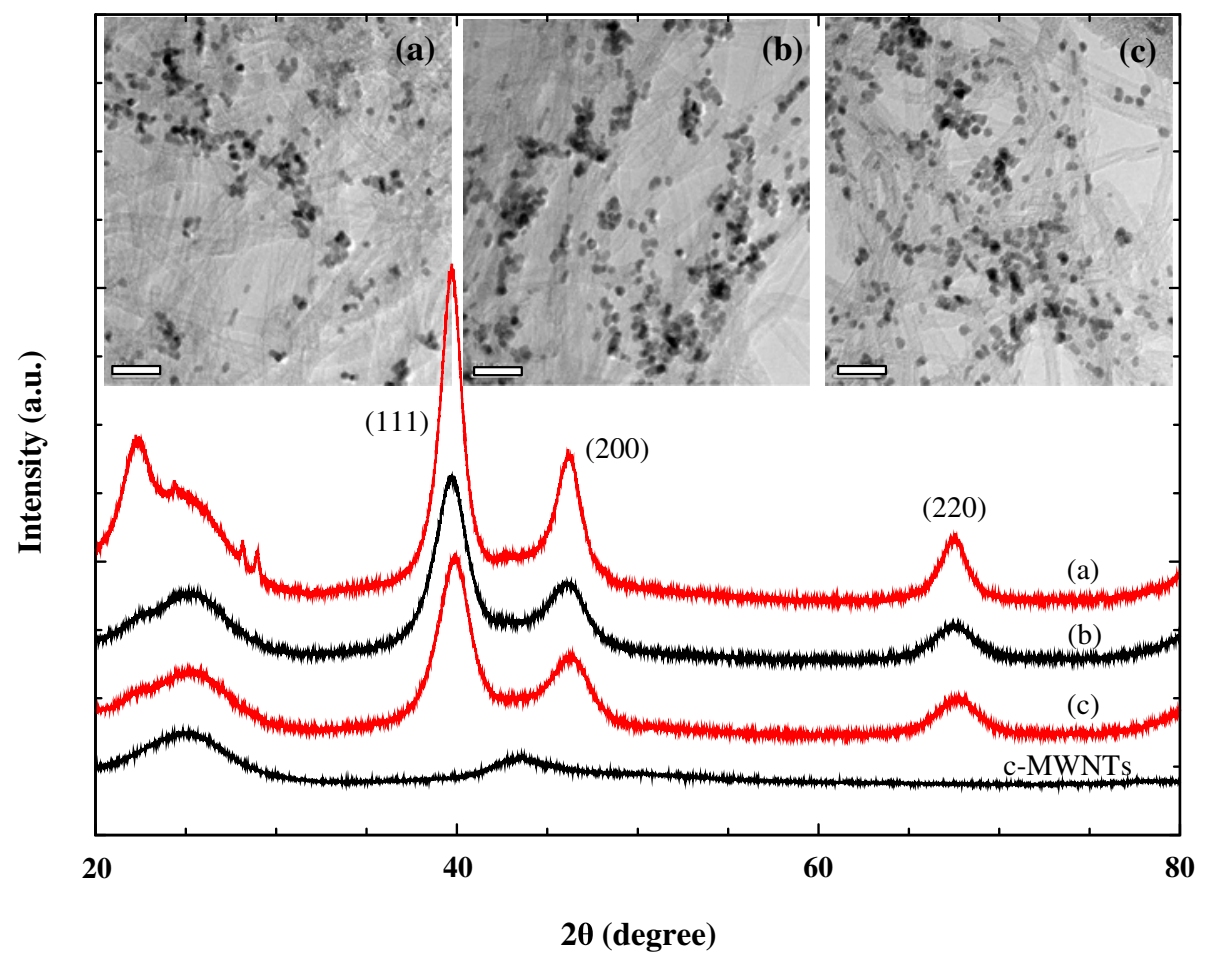

Figure 2. XRD patterns and TEM images of composites: (a) $c-M W N T-P t$, (b) HO-MWNT$\mathrm{Pt}$, (c) $c(\mathrm{HO})-\mathrm{MWNT}-\mathrm{Pt}$. The scale bars in TEM images represent $20 \mathrm{~nm}$. 
were found at $40^{\circ}, 46 \cdot 2^{\circ}$, and $67 \cdot 7^{\circ}$, respectively which corresponded to the characteristic diffractions of Pt nanoparticles (Gao et al 2007). There was not any specific difference among the diffraction peaks. Finding the characteristic diffractions of $\mathrm{Pt}$ indicates that $\mathrm{Pt}$ nanoparticles have been well formed in the chemically-treated MWNTs such as $c$-MWNTs, HO-MWNTs, and $c(\mathrm{HO})-$ MWNTs. When the Pt sizes of the composites were estimated by the Scherrer equation,

$$
B(2 \theta)=K \lambda / L \cos \theta
$$

Pt nanoparticles were calculated to be $3 \cdot 2-4.5 \mathrm{~nm}$ regardless of composites (Langford and Wilson 1978). In addition to XRD patterns, TEM images of the composites were presented in the insets of this figure. Although there was slightly a difference among their morphologies, the sizes of Pt nanoparticles were determined to be $3-5 \mathrm{~nm}$ in their MWNT networks. The estimated sizes from XRD results agreed well with those of TEM images. The nanoparticles were some more agglomerated in HO-MWNT composite than in $c$-MWNT composite. The nanoparticles were relatively well distributed and their aggregation was not serious in $c(\mathrm{HO})-\mathrm{MWNT}$ composite, which were chemically treated in both acid and hydrogen peroxide medium. These morphological changes represent that the distribution of nanoparticles in the chemically-treated MWNTs could be altered by the chemical modification condition, by which carboxylic acid or hydroxyl groups were introduced in the surfaces of MWNTs.

In addition, chemical status of Pt nanoparticles was analysed by XPS experiment of MWNT-Pt composites as shown in figure 3. Sharp doublets of Pt $4 f$ were identified at $71 \cdot 1$ and $74.6 \mathrm{eV}$, which agreed well with literature values (Wang et al 2006). Their shapes and peak positions were similar to one another. The finding of Pt peaks at the same positions indicates that the chemical environments of Pt nanoparticles are almost same in their composites regardless of the difference of chemically-treated MWNTs. Our previous results showed that the interaction between elements could change their chemical environments and correspondingly shift the positions of their binding energies (Lin et al 2005; Bittencourt et al 2008). The asymmetries of Pt peaks were caused by the existence of chemically-different Pt components. The deconvolution of Pt peaks in the inset showed smaller peaks in the higher energies (i.e. $75.7 \mathrm{eV}$ and $72.5 \mathrm{eV}$ ), which were assigned for the Pt oxide. A small amount of Pt oxides could be formed by the chemicallyoxided MWNTs for the chemical treatment of Pt precursors.

The electrocatalytic oxidation behaviours are considered important for the fuel cell application. In order to study the catalytic activities on the electrochemical oxidation of some basic alcohols such as methanol, ethanol, ethylene glycol and butanol, cyclic voltammograms $(\mathrm{CV})$ were measured in $0.5 \mathrm{M} \mathrm{H}_{2} \mathrm{SO}_{4}$ aqueous solution. Figure 4 presents $\mathrm{CV}$ curves of MWNT composites with Pt nanoparticles in the absence of any alcohol. Although any specific signal of electrocatalytic oxidation/reduction was not found from the background CV curves, the capacitive currents were relatively high due to the high active surface area of carbon nanotube itself. The weak oxidation and reduction peaks were observed at $\sim 0.35$ and $\sim 0.4 \mathrm{~V}$, which were caused by the electrochemical redox of fuctionalized groups $(-\mathrm{OH}$ and $-\mathrm{COOH})$ on the surfaces of MWNTs (Gao et al 2007).

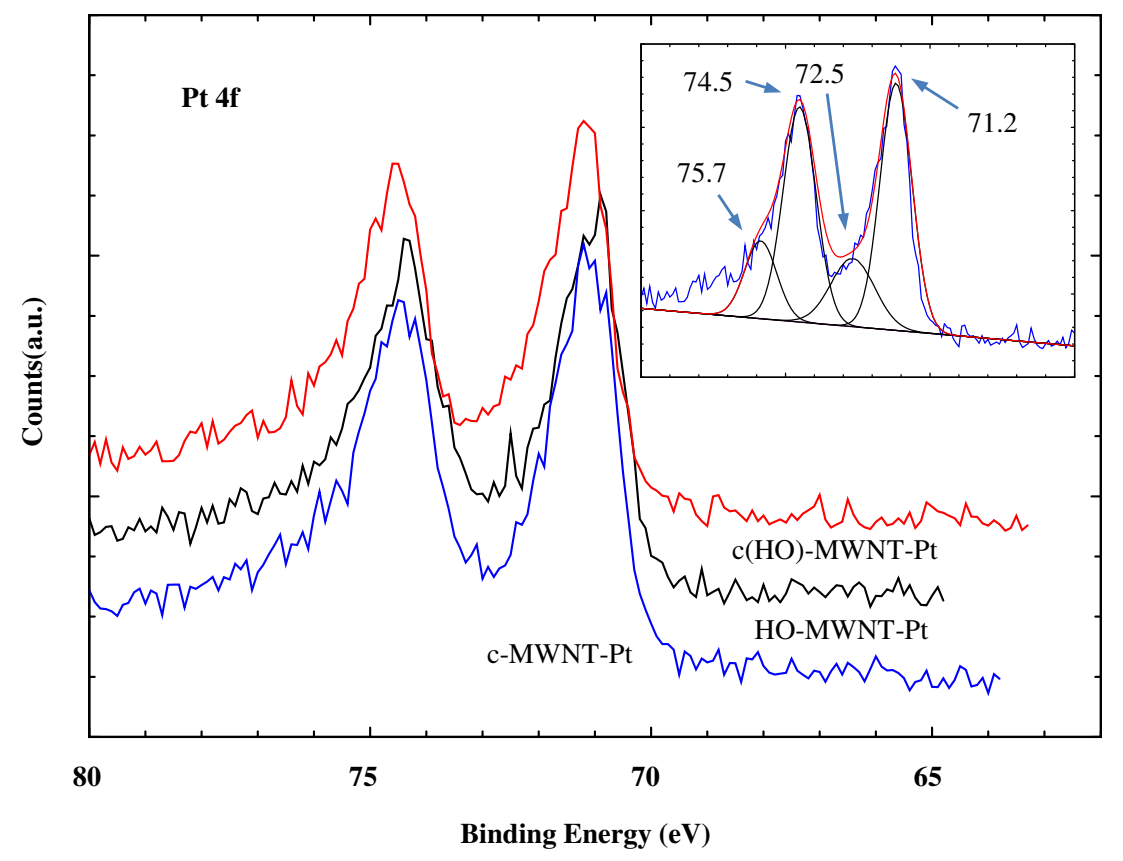

Figure 3. XPS spectra of Pt $4 f$ core level in composites. Inset shows representative peak deconvolution of $c-\mathrm{MWNT}-\mathrm{Pt}$. 
Figure 5 shows analysis of the electrocatalytic activations on alcohols. As compared to figure 4, the cyclic currents were highly improved and the distinct oxidation peaks were identified in the CV curves of figure 5. As described in literature
(Hitmi et al 1994; Fujiwara et al 1999), two distinguished oxidation peaks were found when the $\mathrm{CV}$ was conducted in $\mathrm{H}_{2} \mathrm{SO}_{4}$ aqueous solution with methanol, ethanol or ethylene glycol; the higher potential on forward scanning corresponds

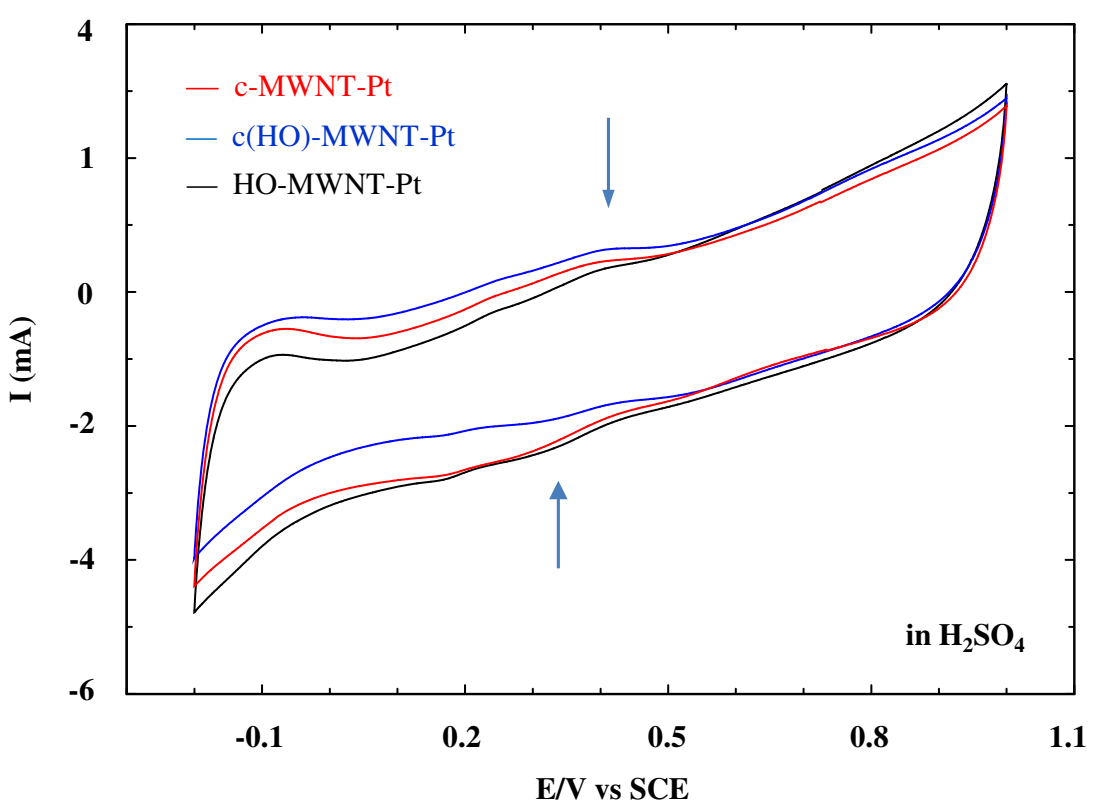

Figure 4. Cyclic voltammograms of chemically-treated MWNTs with Pt nanoparticles, which were conducted in $0.5 \mathrm{M} \mathrm{H}_{2} \mathrm{SO}_{4}$ with a scan rate of $50 \mathrm{mV} / \mathrm{s}$.
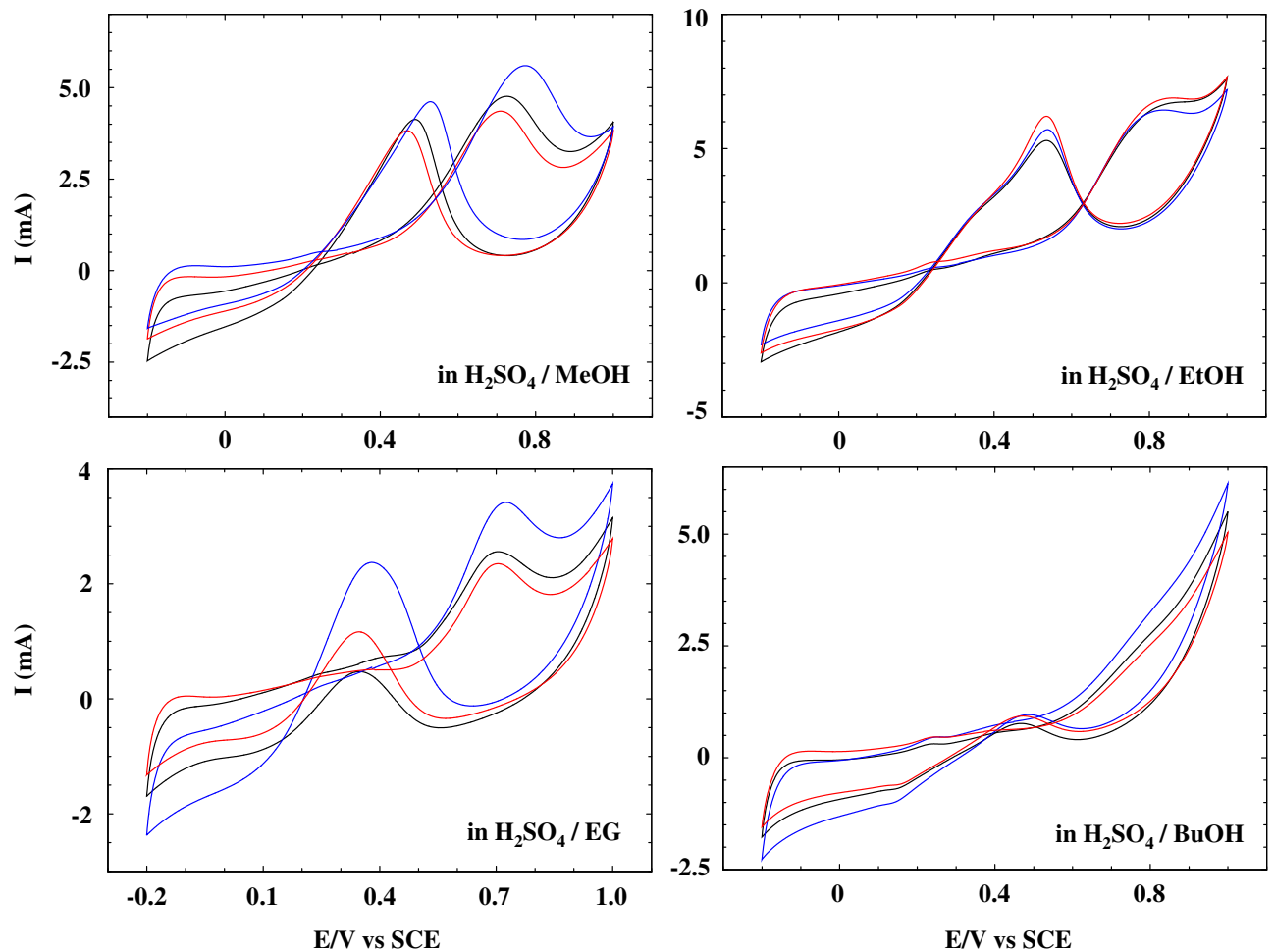

Figure 5. Cyclic voltammograms of some alcohols in chemically-treated MWNTs with Pt nanoparticles, which were conducted in $0.5 \mathrm{M} \mathrm{H}_{2} \mathrm{SO}_{4}$ with a scan rate of $50 \mathrm{mV} / \mathrm{s}$. Each solution was prepared with a mixture of $0.5 \mathrm{M} \mathrm{H}_{2} \mathrm{SO}_{4}$ and $0.5 \mathrm{M}$ alcohol. Red, blue and black lines represent the $\mathrm{CV}$ curves on $c-\mathrm{MWNT}-\mathrm{Pt}, c(\mathrm{HO})-\mathrm{MWNT}-\mathrm{Pt}$, and HO-MWNT-Pt, respectively. 
to the oxidation of alcohol and the generation of $\mathrm{CO}_{2}$, the lower potential on backward scanning to water adsorption and activation on $\mathrm{Pt}$ surfaces. The release of $\mathrm{CO}_{2}$ during alcohol activation was caused by reaction of the activated water and oxidized form of alcohol on Pt surfaces. These characteristic oxidation peaks were separately collected in methanol, ethanol, ethylene glycol and butanol in figure 5, and it was shown that their currents and peak positions were changed with the chemical modification of MWNTs. The oxidation peaks of these $\mathrm{CV}$ curves could be comparable with the previous literature (Chatterjee et al 2009). As neglecting peak current values, we could distinctly find two oxidation peaks in methanol and ethylene glycol solutions. These oxidation peaks were relatively weak in ethanol because of high diffusion currents. However, the absolute current values of ethanol oxidations were very high, indicating good catalytic activities. Especially, the electrocatalytic activities were very weak in case of butanol, in which weak oxidation peaks were just found on backward scanning. As reported in previous literatures (He et al 2004), CV curves in this work showed that MWNT-Pt composites were catalytically active on alcohols, and the activity might be closely related to the surface conditions of chemically-treated MWNTs and the morphologies of Pt-MWNT composites as well as Pt loadings. The higher cyclic current of $c(\mathrm{HO})-\mathrm{MWNT}-\mathrm{Pt}$ in methanol and ethylene glycol indicates that the catalytic activity is improved with the increase of hydroxyl groups in the alcohol molecule. However, longer chained alcohol such as butanol was not effectively catalyzed by these composite systems.

\section{Conclusions}

Some MWNT-Pt composites were prepared and characterized structurally and electrochemically. Prior to the composite preparation, pristine MWNTs were chemically treated with acidic and/or hydrogen peroxide solutions. Through the structural analyses, the chemically-treated MWNTs were identified to be carboxylated and hyroxylated, on both their surfaces. TEM and XRD data showed that Pt nanoparticles were well distributed in MWNTs. Cyclic voltammograms showed that some basic alcohols were effectively activated in the composites. The degree of catalytic activities of the composites was dependent on the kind of alcohols. Ethanol was the most activated in the composites, and the longer-chained butanol was not almost activated in any composite.

\section{References}

An K H, Kim W S, Park Y S, Moon J M, Bae D J, Lim S C, Lee Y S and Lee Y H 2001 Adv. Funct. Mater. 11387

Ang L M, Hor T S A, Xu G Q, Tung C H, Zhao S P and Wang J L S 2000 Carbon 38363
Bittencourt C, Hecq M, Felten A, Pireaux J J, Ghijsen J, Felicissimo M P, Rudolf P, Drube W, Ke X and Van Tendeloo G 2008 Chem. Phys. Lett. 462260

Chan K Y, Ding J, Ren J W, Cheng S A and Tsang K Y J 2008 Mater. Chem. 14505

Chatterjee M, Chatterjee A, Ghosh S and Basumallick I 2009 Electrochim. Acta 547299

Chen X H, Xia J T, Peng J C, Li W Z and Xie S S 2000 Compos. Sci. Technol. 60301

Fujiwara N, Friedrich K A and Stimming U 1999 J. Electroanal. Chem. 472120

Gao G, Yang G, Xu M, Wang C, Xu C and Li H 2007 J. Power Sources 173178

Garcia J, Gomes H T, Serp P, Kalck P, Figueiredo J L and Faria J L 2005 Catal. Today 102-103 101

Gomes H T, Samant P V, Serp P, Kalck P, Figueiredo J L and Faria J L 2004 Appl. Catal. B: Environ. 54175

He Z, Chen J, Liu D, Zhou H and Kuang Y 2004 Diamond Relat. Mater. 131764

Hitmi H, Belgsir E M, Leger J M, Lamy C and Lezna R O 1994 Electrochim. Acta 39407

Hu X, Wang T, Qu X and Dong S 2006 J. Phys. Chem. B110 853

Kim H K and Lee R Y 2009 Kor. J. Mater. Res. 19192

Kong F Z, Zhang X B, Xiong W Q, Liu E, Huang W Z, Sun Y L, Tu J P and Chen X W 2002 Surf. Coating Technol. 15533

Langford J I and Wilson A J C 1978 J. Appl. Cryst. 11102

Lin Y, Cui X, Yen C and Wai C M 2005 J. Phys. Chem. B109 14410

Liu Z, Lin X, Lee J Y, Zhang W, Han M and Gan L M 2002 Langmuir 184054

Liu Z, Ling X Y, Su X, Lee J Y and Gan L M 2005 J. Power Source 1491

Menard D, Py X and Mazet N 2007 Chem. Eng. Process. 46565

Morris C A, Anderson M L, Stroud R M, Merzbacher C I and Rolison D R 1999 Science 284622

Parsons R and VandefNoot T 1988 J. Electroanal. Chem. 2579

Qi Z, Lefebvre M C and Pickup P G 1998 J. Electroanal. Chem. 4599

Selvaraj V, Vinoba M and Alagar M 2008 J. Colloid Interf. Sci. 322 537

Serp P, Corrias M and Kalck P 2003 Appl. Catal. A: Gen. 253337

Sharma S N, Sharma H, Singh G and Shivaprasad S M 2006 Nucl. Instrum. Meth. B244 86

Thompson S D, Jordan L R and Forsyth M 2001 Electrochim. Acta 461657

Tong Y Y, Rice C, Wieckowski A and Oldfield E $2000 \mathrm{~J}$. Am. Chem. Soc. 1221123

Uchida M, Aoyama Y, Tanabe M, Yanagihara N, Eda N and Ohta A 1995 J. Electrochem. Soc. 1422572

Vu H, Goncalves F, Philippe R, Lamouroux E, Corrias M, Kihn Y, Plee D, Kalck P and Serp P 2006 J. Catal. 24018

Wang C, Waje M, Wang X, Tang J M, Haddon R C and Yan Y 2004 Nano Lett. 4345

Wang Y, Xu X, Tian Z, Zong Y, Cheng H and Lin C 2006 Chem. Eur. J. 122542

Wildgoose G G, Banks C E and Compton R G 2006 Small 2182

Wu G, Chen Y S and Xu B Q 2005 Electrochem. Commun. 71237

Xia X H, Iwasita T, Fe F and Vielstich W 1996 Electrochim. Acta 41711

Yoon B and Wai C M 2005 J. Am. Chem. Soc. 12717174 